\title{
ДИФФЕРЕНЦИРОВАННЫЙ УЧЕТ ГЕОМОРФОЛОГИЧЕСКИХ УСЛОВИЙ ВОДОСБОРНОГО БАССЕЙНА С ИСПОЛЬЗОВАНИЕМ ПОРЯДКОВЫХ ХАРАКТЕРИСТИК ВОДОРАЗДЕЛОВ
}

\author{
Шекман $\mathrm{E}$. . \\ Тихоокеанский институт географии ДВО РАН, Владивосток \\ shekman.e@gmail.com
}

Аннотащия. Флагманом современной географии выступает моделирование географических систем и процессов их функционирования, базирующееся на огромных базах данных и алгоритмах многомерного компьютерного моделирования поведения сложных многосвязных систем. Сам процесс моделирования базируется на мощном аппарате математического анализа и статистической обработки базовых параметров объектов, на основе которых производится построение имитационных моделей их функционирования и развития. Речной бассейн является самым распространенным на поверхности суши природным объектом, обладающий отчетливо выраженными границами, структурной организацией, иерархией, относительной замкнутостью потоков вещества и энергии. При описании структуры водосборного бассейна речной системы традиционно применяются порядковые классификации. Порядковая классификация водотоков базируется на основополагающем свойстве речных потоков образовывать при последовательном слиянии древовидную структуру со ступенчатым нарастанием основных параметров системы. Стабильность структуры при этом поддерживается непрерывной деятельностью мощных потоков вещества и энергии. Широкое применение получила нисходящая порядковая классификация Р. Хортона [7], в основу которой легло положение о том, что неразветвленные элементарные водотоки сходны в разных условиях и должны иметь наименьший 1-й порядок, образуя при слиянии водоток 2-го порядка, в то время как водотоки 2-го порядка образуют водоток 3-го порядка и т. д. Также Хортоном, на основе анализа структуры речных сетей и их бассейнов были предложены законы соотношения основных характеристик водотоков разных порядков. Позднее порядковая классификация Хортона была доработана Стралером [6], который исключил понятие «главной реки», которая на всем своем протяжении имеет максимальный порядок, хотя структурно состоит из множества разнопорядковых сегментов. Данные классификации сейчас принято рассматривать в едином контексте как классификацию Хортона-Стралера. Еще в XIX веке был высказан тезис о том, что водоразделы и тальвеги являются главными структурными линиями рельефа и находятся в тесной взаимосвязи [2], определяя распределение потоков вещества и энергии в водосборном бассейне. С использованием классификации водотоков Хортона-Стралера предложен принцип классификации водоразделов. На основе авторской методики обработки цифровых моделей рельефа (ЦМР) с использованием инструментов ГИС было апробировано использование порядковых характеристик водоразделов для получения детальной информации о вариациях основных характеристик однопорядковых элементов речной сети в зависимости от порядка водораздела в пределах бассейна реки Уссури. 
Ключевые слова: речная сеть, порядковая классификация водотоков, порядковая классификация водоразделов, структурно-гидрографический анализ, цифровые модели рельефа.

\title{
DIFFERENTIATED ACCOUNTING OF THE GEOMORPHOLOGICAL CONDITIONS OF THE RIVER BASIN USING THE ORDER CHARACTERISTICS OF WATERSHEDS
}

\author{
Shekman E.A. \\ Pacific Geographical Institute FEB RAS, Vladivostok
}

Annotation. The flagship of modern geography is the modeling of geographical systems and the processes of their functioning, based on huge databases and algorithms for multidimensional computer modeling of the behavior of complex multiply connected systems. The modeling process itself is based on a powerful apparatus for mathematical analysis and statistical processing of the basic parameters of objects, based on which simulation models of their functioning and development are built. The river basin is the most widespread natural object on the land surface, which has distinct boundaries, structural organization, hierarchy, and relative isolation of matter and energy flows. In describing the structure of the catchment of a river system, ordinal classifications are traditionally applied. The ordinal classification of watercourses is based on the fundamental property of river flows to form a tree structure with successive merging with a stepwise increase in the main parameters of the system. The stability of the structure is supported by the continuous activity of powerful flows of matter and energy. The descending ordinal classification of R. Horton [7] was widely used, which was based on the proposition that unbranched elementary watercourses are similar under different conditions and should have the smallest 1st order, forming second order watercourses at the time how 2nd order watercourses form a 3rd order watercourse, etc. Also, Horton, based on an analysis of the structure of river networks and their basins, proposed the laws of correlation of the main characteristics of watercourses of different orders. Later, the Horton ordinal classification was finalized by A. Straler [6], who excluded the concept of the "main river", which along its entire length has the maximum order, although it structurally consists of many different-order segments. Classification data is now considered to be considered in a single context as the Horton-Strahler classification. As early as the 19th century, the thesis was expressed that watersheds and thalwegs are the main structural lines of the relief and are closely interconnected [2], determining the distribution of matter and energy flows in the catchment. Using the classification of Horton-Strahler watercourses, the principle of the classification of watersheds is proposed. Based on the author's methodology for processing digital elevation models (DEM) using GIS tools, the use of ordinal characteristics of watersheds was tested to obtain detailed information on variations of the main characteristics of single-order elements of the river network depending on the order of the watershed within the Ussuri River Basin. 
Key words: river network, ordinal classification of watercourses, ordinal classification of watersheds, structural-hydrographic analysis, digital elevation models.

Моделирование речной сети средствами ГИС на базе цифровых моделей рельефа (ЦМР) является стандартной задачей и наиболее просто реализуется путем задания пороговой площади водосборного бассейна, свыше значения которой образуются первичные водотоки. Построение водоразделов при этом отсутствует в стандартном инструментарии ГИС, набор инструментов которых ограничивается процедурами построения водосборных бассейнов или же их границ путем конвертации в полигональные, а затем в линейные объекты. При необходимости же построить сеть водоразделов, зачастую опираются на процедуру инвертирования значений ЦМР и повторения всего алгоритма построения речной сети, но уже моделируя таким способом водоразделы. В отличие от речной сети водоразделы не обладают строгой упорядоченностью, в результате чего результат представляет собой достаточно хаотично расположенную бессистемную сеть линий водоразделов.

Слабая методическая проработка данного вопроса связана, прежде всего, с отсутствием на данный момент фундамента для широкого теоретического и практического применения данных о структуре водоразделов. Описание структуры водоразделов, их классификация и другие построения на их базе легли в основу школы структурной морфометрии [1], разработавшей морфометрический метод поисков тектонических структур, который получил признание у геологов, геоморфологов и географов. Методологические приемы морфометрического анализа, предложенные В.П. Философовым, базировавшиеся на массовой обработке топографического материала, в дальнейшем успешно трансформировались и для обработки ЦМР.

Другой слабой стороной данного вопроса является отсутствие логической обоснованности подхода к порядковой классификации линий водоразделов, когда порядки водоразделов и водотоков назначаются независимо друг от друга при очевидном наличии строгой взаимосвязи и соподчиненности.

При классификации водоразделов стоит исходить из необходимости взаимосвязи порядковых характеристик. В любом элементарном речном бассейне водораздел и водоток объединяет общее направление потоков вещества и энергии к замыкающему створу, таким обра- 
зом, видится возможным разработка классификация водоразделов в рамках единой порядковой концепции с речной сетью, основываясь на пути стока с водораздела до замыкающего створа по водотокам разных порядков. При суммировании растровых мозаик водоразделов происходит идентификация порядковой последовательности стока. Например, последовательность для участка водораздела бассейна реки пятого порядка в виде $\mathrm{x} 5-\mathrm{x} 4-\mathrm{x} 3-\mathrm{x} 2-\mathrm{x} 1$ или 54321 будет означать, что это участок водораздела пятого порядка, сток с которого проходит через все возможные порядки речной сети данного бассейна, или же х5 - x0 - x0 - x2 - х1 или 50021, будет означать, что это участок водораздела второго порядка, сток с которого осуществляется, минуя водотоки 3 и 4 порядков, в главную реку пятого порядка. Таким образом, обеспечивается обоснованное соответствие структуры и порядковой классификации речной сети и водоразделов.

Главной задачей при моделировании структурных элементов речного бассейна является корректное задание условий их выделения. Современные подходы к моделированию гидрографической сети средствами ГИС опираются на обработку цифровых моделей рельефа (ЦМР) с применением различного рода индексов, используемых для параметризации условий существования постоянного водотока на основе разных критериев. Широкое применение получило использование задания пороговой площади водосбора, исходя из эмпирической зависимости между площадью водосбора и аккумулируемым стоком. Также используются и другие, более сложные индексы, оперирующие дополнительными морфометрическими и литологическими характеристиками.

Построение сети водоразделов в данной ситуации является сопряженной задачей, корректность выполнения которой полностью зависит от возможности корректной реализации моделирования гидрографической сети.

В качестве методической основы для моделирования в данной работе служит использование «комплексного энергетического индекса» (Complex Energy Index, CEI) [4], который представляет собой функцию от климатического стока и морфометрических условий рельефа в каждой точке бассейна, обеспечивая, таким образом, независимую параметризацию геоморфологических и гидроклиматических условий формирования речной сети [3]. Учет геологических и литологических условий осуществляется путем калибровки оптимального 
порогового значения индекса CEI, достигая максимального соответствия с реальной речной сетью, полученной путем ручной оцифровки по топографическим картам масштаба, сопоставимого с разрешением используемой ЦМР.

$$
E_{i}^{*} \propto A_{i}(P-E T) \Delta z_{i}
$$

где $A_{i}$ - площадь водосбора в точке $i, \Delta z_{i}-$ локальный уклон, $P-E T-$ климатический сток

Полученная модель выступает основой для построения отдельных растровых мозаик границ водосборов рек разных порядков.

Отсутствие единообразия в подходах к моделированию сети водоразделов потребовало разработки специального алгоритма, обеспечивающего возможность на основе мозаики частных водосборных бассейнов разных порядков производить выделение границ частных водосборов каждого порядка, с их последующим наложением и классификацией в полной увязке с порядковой структурой речной сети.

Методологические приемы для построения речной сети [4] и водоразделов [5] были успешно применены и апробированы для ряда малых (до 6 тыс. км²) и средних (до 20 тыс. км²) по площади речных бассейнов юга Дальнего Востока России с широким спектром физико-географических условий.

По Хортону предполагается, что реки одинаковых порядков имеют сходные морфометрические характеристики, при этом, исходя из неоднородности условий в пределах водосборных бассейнов, видится вполне логичным предположение, что элементарный водоток 1-го порядка, расположенный близ главного водораздела, должен иметь отличные характеристики от водотока 1-го порядка, впадающего в главную реку близ устья. Для проверки данного предположения были смоделированы сети водотоков и водоразделов для бассейна р. Уссури с замыкающим створом пос. Кировский.

В таблице 1 приведены средние характеристики водотоков 1-го порядка. Как можно видеть из таблицы 2 , в зависимости от порядка соответствующего водораздела данные характеристики могут испытывать существенные вариации. Степень закономерности изменений с возрастанием порядка водораздела во многом зависит от однородности и органичности развития бассейна в целом. Для бассейна Уссури на 5-6 порядках водоразделов наблюдается нарушение общей тенденции изменения ряда характеристик в результате добавления к 
массиву данных результатов моделирования по бассейну впадающей в нее р. Арсеньевка, которая существенно отличается по структуре и характеру развития сети водотоков. При этом можно говорить об общей тенденции к нарастанию уклонов водотоков и средней высоты их частных водосборов с нарастанием порядка водораздела. Средние площади частных водосборов наоборот понижаются.

\section{Таблица 1}

\section{Средние характеристики} водотоков 1-го порядка бассейна р. Уссури

\begin{tabular}{|l|c|}
\hline Число водотоков & 8198 \\
\hline Длина водотока (м) & 1076 \\
\hline Площадь бассейна (км²) & 1,67 \\
\hline Уклон водотока (м/км) & 16,47 \\
\hline Уклон водосбора (м/км) & 23,84 \\
\hline Высота водосбора (м) & 642,8 \\
\hline
\end{tabular}

Та блица 2

Средние характеристики водотоков 1-го порядка бассейна р. Уссури в зависимости от порядка соответствующего им водораздела.

\begin{tabular}{|l|c|c|c|c|c|c|c|c|}
\hline Порядок водораздела & 1 & 2 & 3 & 4 & 5 & 6 & 7 & 8 \\
\hline Число водотоков & 2287 & 2032 & 1515 & 981 & 419 & 746 & 81 & 137 \\
\hline Длина водотока (м) & 1356 & 1046 & 912 & 838 & 979 & 1021 & 908 & 1051 \\
\hline Площадь бассейна (км²) & 1,98 & 1,69 & 1,46 & 1,33 & 1,67 & 1,6 & 1,42 & 1,7 \\
\hline Уклон водотока (м/км) & 14,32 & 15,83 & 18,24 & 19,34 & 16,07 & 17,72 & 18,75 & 15,06 \\
\hline Уклон водосбора (м/км) & 23,26 & 23,13 & 24,53 & 25,40 & 22,40 & 24,90 & 24,13 & 23,82 \\
\hline Высота водосбора (м) & 559,7 & 594,4 & 655,0 & 739,7 & 700,5 & 775,1 & 864,4 & 890,5 \\
\hline
\end{tabular}

Данный пример демонстрирует перспективность использования порядковых характеристик водоразделов для водотоков разных порядков для более детального описания структурной организации бассейна и массового получения статистических данных.

Исследование выполнено при финансовой поддержке РФФИ (проект №19-05-00353)

\section{Литература}

1. Философов В.П. Основы морфометрического метода поисков тектонических структур. Саратов: Изд-во Саратовского ун-та, 1975. 232 с. 
2. Cayley A. On contour and slope lines // Edinburg and Dublin Philosophical Magazine and Journal of Science. 1859. Vol. 18. № 4. P. 264-268.

3. Gartsman B.I. Analysis of geomorphological conditions for primary streams formation using digital elevation models // Geography and Natural Resources. 2013. Vol. 34. № 1. P. 69-78.

4. Gartsman B.I., Shekman E.A. Potential of river network modeling based on GIS technologies and digital elevation model // Russian Meteorology and Hydrology. 2016. Vol. 41. № 1. P. 63-71.

5. Gartsman B.I., Shekman E.A., Lee K.T. Order classification of river watershed divides based on processing digital elevation models // Geography and Natural Resources. 2016. Vol. 37. № 4. P. 362-370.

6. Strahler A.N. Hypsometric (area-altitude) analysis of erosional topography // Geol. Soc. Am. Bull. 1952. Vol. 63. P. 1117-1142.

7. Horton R.E. Erosional Development of Streams and their Drainage Basins: Hydrophysical Approach to Quantitative Morphology // Geol. Soc. Amer. Bull. 1945. №. 56. P. 275-370.

\section{References}

1. Filosofov V.P. Osnovy morfometricheskogo metoda poiskov tektonicheskih struktur [Fundamentals of the morphometric parameter of the search for tectonic structures]. Saratov, Saratov Univ. Publ., 1975. 232 p. [in Russian].

2. Cayley A. On contour and slope lines. Edinburg and Dublin Philosophical Magazine and Journal of Science, 1859, vol. 18, no. 4, pp. 264-268.

3. Gartsman B.I. Analysis of geomorphological conditions for primary streams formation using digital elevation models. Geography and Natural Resources, 2013, vol. 34, no. 1, pp. 69-78.

4. Gartsman B.I., Shekman E.A. Potential of river network modeling based on GIS technologies and digital elevation model. Russian Meteorology and Hydrology, 2016, vol. 41, no. 1 , pp. 63-71.

5. Gartsman B.I., Shekman E.A., Lee K.T. Order classification of river watershed divides based on processing digital elevation models. Geography and Natural Resources, 2016, vol. 37, no. 4, pp. 362-370.

6. Strahler A.N. Hypsometric (area-altitude) analysis of erosional topography. Geol. Soc. Am. Bull., 1952, vol. 63, pp. 1117-1142.

7. Horton R.E. Erosional Development of Streams and their Drainage Basins: Hydrophysical Approach to Quantitative Morphology. Geol. Soc. Amer. Bull., 1945, no. 56, pp. 275-370. 